\title{
Аллергический бронхолегочный аспергиллез: проблемы диагностики и терапии
}

\author{
1 - ФГУ НИИ пульмонологии ФМБА России: 105077, Москва, ул. 11-я Парковая, 32, к. 4; \\ 2 - НИИ медицинской микологии им. П.Н.Кашкина Санкт-Петербургской медицинской академии последипломного образования: 194291, Санкт-Петербург, \\ ул. Сантьяго-де-Куба, 1/28; \\ 3 - Институт биоорганической химии им. М.М.Шемякина и Ю.А.Овчинникова: 117997, Москва, ул. Миклухо-Маклая, 16/10
}

\section{A.V.Kuleshov, V.S.Mitrofanov, E.V.Svirshcherskaya \\ Allergic bronchopulmonary aspergillosis: issues of diagnosis and therapy}

Key words: allergic bronchopulmonary aspergillosis, itraconazole.

Ключевые слова: аллергический бронхолегочный аспергиллез, итраконазол.

Впервые классическое описание аллергического бронхолегочного аспергиллеза (АБЛА) было сделано в 1952 г. K.F.Hinson et al. [1]. С тех пор частота выявления случаев этого заболевания возрастает с каждым годом во всех странах. В настоящее время термин "АБЛА" широко известен среди пульмонологов и аллергологов. Однако, несмотря на это, своевременная диагностика АБЛА остается довольно трудной задачей, и в России данная патология выявляется редко. Ранее это связывали с отсутствием лабораторных диагностических тестов, однако в настоящее время они широко доступны. Проблема, главным образом, состоит в том, что АБЛА по-прежнему считают редким заболеванием и не рассматривают при дифференциальной диагностике патологических процессов со схожими симптомами, что можно связать, прежде всего, с недостатком информации по выделению групп риска и расплывчатостью диагностических критериев. Имея опыт наблюдения > 40 больных АБЛА, мы хотели бы обсудить проблемы диагностики и лечения этого заболевания.

\section{Частота заболевания}

Сведений о встречаемости АБЛА в общей популяции нет. Частота выявления АБЛА среди больных бронхиальной астмой (БА) значительно колеблется (табл. 1).

Выделение группы риска имеет ключевое значение для идентификации АБЛА среди больных БА. V.Maurya et al. [8] обследовали 105 больных БА с помощью кожных тестов, включая пробу с антигеном Aspergillus, определение общего иммуноглобулина $\mathrm{E}(\mathrm{IgE})$, клинический анализ крови и рентгенограмму легких. Диагноз АБЛА устанавливали при соответствии всех 8 "больших" критериев. У 28,5 \% обследованных был положительным тест на Aspergillus, у $11(10,4 \%)$ - специфический тест на иммуноглобулин $\mathrm{G}(\mathrm{IgG})$ и у $8(7,6 \%)$ - на сывороточные преципитины. У 8 из этих 30 больных установлен диагноз АБЛА (26,6 \%), т. е. у 7,6\% от всей обследованной группы. В ходе наблюдения был сделан важный вы- вод: сенсибилизация к Aspergillus существенно утяжеляет течение БА.

Ранее T.Eaton et al. [10] обследовали 255 пациентов с БА, которым был произведен кожный тест: у 218 из 255 (86,8 \%) была атопическая форма, а у 47 из 255 (21\%) - положительные пробы с антигеном Aspergillus fumigatus (A. fumigatus), из которых 35 больным была выполнена компьютерная томография (КТ). Диагноз АБЛА, соответствуюший всем основным критериям, был установлен у 9 из 35 больных (25,7 \%), минимальным критериям соответствовали 13 пациентов $(37,1 \%)$. Было сделано заключение, что сенсибилизация к A. fumigatus отмечена у $20 \%$ больных БА. Диагноз АБЛА был подтвержден посредством КТ у 25-49 \% таких больных - в зависимости от критериев диагноза. Сделан вывод, что проведение кожного теста с антигеном Aspergillus может быть скриннинговым методом отбора пациентов для КТ в связи с подозрением на АБЛА.

\section{Патогенез АБЛА}

Современные представления о патогенезе АБЛА определяют это заболевание как комбинированную аллергическую реакцию в ответ на колонизацию дыхательных путей плесневыми грибами A. fumigatus. Колонизация дыхательных путей становится возможной вследствие повреждения легочного клиренса. АБЛА крайне редко развивается как первичная форма БА. И наоборот, развитие АБЛА у больных БА связывают с предрасполагающими условиями для колонизации дыхательных путей спорами грибов. В случае прорастания спор гифы повреждают мукоцилиарный клиренс и продуцируют ряд вирулентных факторов.

К вирулентным факторам относят риботоксин Asp f1 и сериновую протеазу Asp f13, которые вызывают деградацию межклеточного матрикса, ингибируют фагоцитоз и киллинговую способность фагоцитирующих клеток (макрофагов, нейтрофилов). Возможно, имеется и некоторая генетическая предрасположенность, связанная с врожденной особенностью 
Частота выявления АБЛА у пациентов с БА

\begin{tabular}{|c|c|c|c|}
\hline Год & Автор (страна) & Выборка & Частота, \% \\
\hline 1968 & A.H.Henderson et al. (Великобритания) [2] & 46 пациентов с БА из пульмонологического отделения & $11-22$ \\
\hline 1981 & J.E.Basich et al. (США) [3] & 42 амбулаторных пациента со стероидозависимой БА & $7-14$ \\
\hline 1985 & A.Chetty et al. (Индия) [4] & 107 амбулаторных детей с персистирующей БА & 15 \\
\hline 1988 & P.A.Greenberger, R.Patterson (США) [5] & $\begin{array}{l}531 \text { амбулаторный пациент с БА и положительными кожными пробами } \\
\text { к грибам рода Aspergillus }\end{array}$ & 6 \\
\hline 1991 & H.J.Schwartz, P.A.Greenberger (США) [6] & $\begin{array}{l}100 \text { амбулаторных пациентов с БА и положительными кожными пробами } \\
\text { к грибам рода Aspergillus }\end{array}$ & 28 \\
\hline 2000 & R.Kumar, S.N.Gaur (Индия) [7] & 200 пациентов с БА, периодически получавших сГКС & 16 \\
\hline 2007 & V.Maurya et al. (Индия) [8] & 105 пациентов с БА & 7,6 \\
\hline 2005 & А.В.Кулешов (Россия) [9] & 180 пациентов с БА в пульмонологическом стационаре & 3,6 \\
\hline
\end{tabular}

Примечание: сГКС - системные глюкокортикостероиды.

системы легочного сурфактанта. Протеазы, высвобождаемые A. fumigatus, также способствуют активации эпителиальных клеток и системы врожденного иммунитета. В норме врожденная иммунная система эффективно удаляет споры всех грибов из бронхов. В случае большой нагрузки формируется Th1-ответ без эозинофилии и IgE. Для того чтобы сформировались мицелиальный рост и последующая споруляция на фоне $\operatorname{IgE~или~эозинофилии,~требуется~ряд~}$ условий [11]:

1) иммунный дефицит со снижением числа нейтрофилов на фоне атопии;

2) наличие предрасполагающих факторов для удержания спор, например повышенной влажности в легких при БА;

3) наличие каких-либо хронических заболеваний, которые вызывают ответ иммунной системы, также и при наличии атопии;

4) повышенная антигенная нагрузка, например у лиц, работающих с зараженными грибами материалами (сено, зерно, мусор), на фоне атопии.

Хроническое воспаление, инфильтрация в легких ведут к ремоделированию дыхательных путей, формированию бронхоэктазов, легочного фиброза и развитию дыхательной недостаточности. В то же время значение бронхоэктазов в патогенезе АБЛА до сих пор не вполне определено: бронхоэктазы могут быть результатом длительного течения АБЛА, но также и местом первичной колонизации грибами и, как следствие, источником сенсибилизации, т. е. причиной формирования АБЛА. Так, мы наблюдали пациента с дистальными мешотчатыми бронхоэктазами, вероятно, врожденного характера, нетипичными для классического АБЛА.

\section{Критерии диагностики АБЛА}

Широко известны следующие критерии диагноза АБЛА [12]:

1) БА (независимо от степени тяжести);

2) персистирующие и транзиторные инфильтраты в легких (считаются необязательными для постановки диагноза АБЛА);

3) положительные кожные пробы с антигеном A. fumigatus;

4) эозинофилия периферической крови > 500 в мм ${ }^{3}$ (необязательна для постановки диагноза АБЛА);
5) определение специфических $\operatorname{IgE}$ и $\operatorname{IgG}$ к A. fumigatus;

6) уровень общего IgE > 1000 нг/мл (1 000 нг 417 ед.; 1 ед. = 2,4 нг);

7) выделение культуры грибов A. fumigatus из мокроты или промывных вод бронхов (необязательно для постановки диагноза АБЛА);

8) наличие центральных бронхоэктазов.

Такой набор критериев даже с первого взгляда представляется слишком громоздким. К тому же почти к каждому из них необходим комментарий. Чтобы определить значимость критериев диагноза и выделить из них главные, их удобно разделить на 3 группы - клинические, рентгенологические и лабораторные (табл. 2).

При оценке клинических критериев следует помнить, что, несмотря на важность наличия БА, правильнее было бы обозначить этот критерий как синдром бронхиальной обструкции. Дело в том, что симптомы БА могут присоединяться позднее, уже после появления инфильтратов и длительного лечения пациента от предполагаемой пневмонии и туберкулеза. Рентгенологические критерии также не являются универсальными: они только подтверждают диагноз АБЛА, но не исключают его. Так, инфильтраты в момент обращения больного или на фоне применения сГКС могут отсутствовать, однако при сборе анамнеза следует обратить внимание на неоднократно перенесенную пневмонию. Наиболее часто при дифференциальной диагностике АБЛА рассматривают туберкулез, а пациенты нередко получают длительное

Таблица 2 Критерии диагностики АБЛА

\begin{tabular}{|c|c|c|}
\hline Клинические & Рентгенологические & Лабораторные \\
\hline \multirow[t]{5}{*}{ БА } & $\begin{array}{c}\text { "Летучие" инфильтраты } \\
\text { в легких }\end{array}$ & Эозинофилия \\
\hline & $\begin{array}{l}\text { Центральные } \\
\text { бронхоэктазы }\end{array}$ & $\begin{array}{c}\text { Высокий уровень } \\
\text { общего lgE }\end{array}$ \\
\hline & & $\lg \mathrm{E}$ к $A$. fumigatus \\
\hline & & $\lg G \times A$. fumigatus \\
\hline & & $\begin{array}{c}\text { Выделение } A \text {. fumigatus } \\
\text { в мокроте }\end{array}$ \\
\hline
\end{tabular}

Примечание: в таблицу не включены кожные пробы с A. fumigatus, поскольку эти тесты и определение специфических lgE к A. fumigatus взаимозаменяемы, а проведение кожных тестов не всегда является возможным (например, при тяжелой гормонозависимой БА, применении ГКС, антигистаминных препаратов и т. п.). 
лечение туберкулостатическими препаратами. В подобных случаях наличию высокой эозинофилии, симптомам БА, которые могут присоединяться позднее, уже на фоне инфильтрации, значения обычно не придают. Серьезной проблемой является и то, что рентгенологическая картина АБЛА не обладает какой-либо существенной спецификой. Ни в одном наблюдаемом случае диагноз АБЛА не был установлен или даже предположен на основании только лишь рентгенологического исследования. Сложные рентгенологические симптомы, такие как "трамвайные рельсы", "перчаточный палец" или "зубная паста", распознаются крайне редко. При оценке рентгенограмм у лиц с подозрением на АБЛА следует обратить внимание на важнейший момент - выявление бронхоэктазов. Выявление бронхоэктазов у больных БА делает диагноз АБЛА высоко вероятным. Для обнаружения бронхоэктазов целесообразно использовать компьютерную томографию (КТ) высокого разрешения. В наших наблюдениях у ряда больных бронхоэктазы, ранее не определяемые на обычных рентгенограммах, легко обнаруживались на КТ. Таким образом, выявление бронхоэктазов (как важнейшего симптома АБЛА) зависит от технических методов.

Однако следует отметить, что в настоящее время наличие бронхоэктазов больше не является критерием, обязательным для постановки диагноза АБЛА [12], поскольку описаны варианты течения этого заболевания и без бронхоэктазов. Выделяют 2 формы АБЛА: АБЛА с центральными бронхоэктазами и серопозитивный АБЛА, при котором диагноз установливается только на основе лабораторного исследования, т. е. без рентгенологических признаков.

Лабораторные критерии также не являются однозначными. Эозинофилия периферической крови на момент обследования может отсутствовать в случаях, когда процесс находится в фазе ремиссии или пациент получает сГКС (например, при гормонозависимой БА). Необходимо тщательное изучение анамнеза, включая амбулаторные карты и выписки из стационаров, где иногда на фоне обострения заболевания можно обнаружить эпизоды эозинофилии. Уровень общего IgE при обострении АБЛА обычно очень высокий (> 1000 ед./мл), однако и этот показатель подвержен значительным колебаниям. В руководствах обычно указывают цифру 1000 нг/мл (мкг/л), в то время как клинические лаборатории обычно представляют результаты, исчисляемые в ед./мл. Это приводит к некоторой путанице при оценке результатов, т. К. 1 ед. равна 2,4 нг и соответствующий классическим критериям показатель $\mathrm{IgE}$ при пересчете на единицы резко понижается и становиться равен чуть более 400 ед./мл. Опять же, если процесс находится в ремиссии или пациент получает сГКС, то этот показатель может быть еще ниже. Также следует помнить, что IgE-опосредованные аллергические реакции можно наблюдать и при нормальных показателях общего IgE.

Таким образом, из всего перечня критериев для постановки диагноза АБЛА принципиально важными и необходимыми являются лишь 3: БА (синдром бронхиальной обструкции), выявление специфических IgE и IgG к A. fumigatus, без которых верифицировать диагноз АБЛА просто невозможно. Кожные пробы (прик-тест) с антигеном Aspergillus, несомненно, являются полезным исследованием, но во многих случаях проведение его ограничено тяжестью заболевания или приемом медикаментов, которые могут влиять на его результат (те же ГКС или антигистаминные средства), однако главной проблемой этого метода является отсутствие стандартных антигенов для постановки кожных проб. В целом определение специфических IgE и IgG к A. fumigatus является стандартным методом диагностики АБЛА, причем более стабильным.

Симптомы и лабораторные показатели, которые делают диагноз АБЛА возможным или высоко вероятным, представлены в табл. 3.

Таким образом, можно выделить следующие клинические состояния, при которых необходимо искЛючить АБЛА:

- любая БА, резистентная к стандартной терапии;

- инфильтративный процесс в легких, сопровождающийся эозинофилией;

- БА с инфильтратами в легких и / или с бронхоэктазами;

- тяжелая гормонозависимая БА;

- другие легочные процессы с выявлением высокого уровня общего $\mathrm{IgE}$.

Во всех случаях диагноз АБЛА подтверждается получением положительных специфических IgE и IgG серологических тестов в сочетании с повышенным уровнем IgЕ. Следует помнить, что высокий уровень общего IgE встречается при ряде других заболеваний, включая атопический дерматит, глистные инвазии, миелому, аспергиллему, аллергический аспергиллезный синусит и аллергическую БА. Применение ГКС может снижать и нормализовать уровень общего IgE. Поэтому, хотя высокий уровень IgE и является одним из основных критериев АБЛА, более чем в $1 / 3$ случаев он может быть существенно ниже, чем указано в диагностических критериях. Однако нормальный уровень общего IgE делает диагноз АБЛА менее вероятным. Кроме того, уровень IgE может быть использован для оценки ответа на проводимое

Таблица 3

Диагностическая ценность клинических, лабораторных и серологических критериев АБЛА

\begin{tabular}{|l|l|}
\hline \multicolumn{1}{|c|}{ Исследования } & Диагностическая ценность \\
\hline Клинические или общие лабораторные & \\
\hline БА & АБЛА возможен \\
\hline $\begin{array}{l}\text { эозинофилия } \\
\text { "летучие" легочные инфильтраты }\end{array}$ & АБЛА возможен \\
\hline $\begin{array}{l}\text { центральные бронхоэктазы } \\
\text { Серологические тесты }\end{array}$ & АБЛА возможен \\
\hline IgE к A. fumigatus & Все тесты положительные - \\
& диагноз подтвержден, \\
\hline $\begin{array}{l}\text { IgG к A. fumigatus } \\
\text { общий IgE }>\text { 400 ед./мл }\end{array}$ & 2 положительных теста - \\
& диагноз высоко вероятен
\end{tabular}


лечение, и повышение его может указывать на обострение АБЛА.

Пациентов с АБЛА обычно ведут как больных гормонозависимой или резистентной к терапии БА или, если присутствуют легочные инфильтраты, туберкулезом легких. Следует констатировать, что практически во всех наших наблюдениях выявление АБЛА носило случайный характер и по-прежнему остается прерогативой специализированных учреждений. Основным заболеванием, с которым проводится дифференциальная диагностика АБЛА при наличии бронхоцентрических инфильтратов, является туберкулез легких.

Развитие тяжелых форм АБЛА является следствием длительного течения, отсутствием своевременной диагностики и специфического лечения. Нередко до установления диагноза АБЛА проходит значительное время (в наших наблюдениях - до 17 лет), что приводит к развитию множества бронхоэктазов, пневмофиброза и существенному снижению легочной функции. Однако это заболевание может развиваться в гораздо более короткие сроки. Под нашим наблюдением находилась пациентка с диагнозом АБЛА, который был установлен лишь спустя 6 мес. от начала клинических проявлений. За это время мы наблюдали все основные этапы, которые проходит больной АБЛА порой за очень длительный период: пневмонию, расцененную как внебольничную, протекающую с выраженной эозинофилией; появление на этом фоне приступов удушья, типичных для БА. Учитывая, что инфильтрация на фоне терапии антибиотиками широкого спектра не разрешалась, появилось подозрение на наличие туберкулезного процесса и были назначены туберкулостатические средства. Лишь после этого совершенно случайно был установлен диагноз АБЛА.

С учетом изменения диагностических критериев в течении АБЛА выделяют 5 стадий (табл. 4) [13].

\section{Лечение АБЛА}

Терапия АБЛА включает в себя комбинацию ГКС и итраконазола (A-I) [14]:

- острая стадия - сГКС (преднизолон 0,5-1,0 мг/Кг до стойкого купирования обструктивного синдрома);

- антифунгальная терапия (итраконазол 200-400 мг в сутки в течение 2-4 мес.).

Лечение обострения АБЛА обычно начинают с назначения сГКС в дозе 0,5-1 мг/кг из расчета на преднизолон. Прежде всего это касается "классических" случаев с наличием инфильтратов и выраженной бронхиальной обструкции. Назначение антифунгальной терапии в острый период может привести к резкому ухудшению состояния, что связывают с высвобождением большого количества антигенного материала вследствие распада возбудителя. В подобных случаях нарастала бронхиальная обструкция, усиливалась инфильтрация в легких и даже появлялись новые инфильтраты. Хотя на фоне терапии сГКС обычно удается достигнуть стабилизации процесса, без проведения антифунгальной терапии возможно быстрое наступление рецидива, а иногда приходится назначать постоянную поддерживающую дозу, что приводит к развитию серьезных побочных эффектов. Следует отметить, что плацебоконтролируемых или двойных слепых исследований по применению ГКС при АБЛА не проводилось, однако клиническая практика отмечает несомненную пользу и высокую эффективность их применения при обострениях этого заболевания.

Роль ингаляционных ГКС (иГКС) в лечении АБЛА остается не вполне определенной. При большом количестве мокроты и выраженной бронхиальной обструкции, что обычно наблюдается в период обострения АБЛА, назначение иГКС представляется малоэффективным. По нашему опыту, применение этих препаратов позволяет контролировать симптомы БА в период ремиссии АБЛА, однако они не оказывают никакого действия на инфильтрацию в период обострения.

Антифунгальной терапии подлежат все выявленные случаи АБЛА. Целью антифунгальной терапии при АБЛА является удаление инфекционного агента, находящегося в дыхательных путях, - постоянного источника аллергенов, что может привести к стойкой ремиссии и достижению контроля над БА. Препаратом выбора для лечения АБЛА является итраконазол. Использование новых азолов, таких как вориконазол, описано лишь для отдельных случаев данной патологии [15] и пока не нашло широкого применения в связи с недостатком данных и высокой стоимостью такой терапии. Основным результатом лечения противогрибковыми средствами может быть переход с сГКС на иГКС и контроль симптомов БА, что подтверждено контролируемыми исследованиями. Рандомизированное контролируемое исследование, в котором одна группа больных АБЛА $(n=55)$ получала итраконазол 400 мг в сутки в течение 16 нед., а другая - плацебо, показало, что в первой из них было меньше обострений, требующих назначения сГКС, а также регистрировалось снижение уровня общего IgE и IgG к A. fumigatus [16]. Несмотря

Таблица 4

Критерии различных стадий АБЛА

\begin{tabular}{l|l|c|c}
\multicolumn{1}{c|}{ Стадия } & \multicolumn{1}{|c}{ Рентгенологические инфильтраты } & Уровень общего IgE & \multicolumn{1}{c}{ Комментарии } \\
\hline I (острая) & Верхняя / средняя доли & $\uparrow \uparrow$ & \\
\hline II (ремиссия) & Нет & $\uparrow /$ норма & Отсутствие инфильтратов >6 мес. после отмены сГКС \\
III (обострение) & Верхняя / средняя доли & $\uparrow \uparrow$ & Подъем общего IgE более чем в 2 раза \\
\hline IV (гормонозависимая БА) & Обычно отсутствуют, но могут и определяться & $\uparrow /$ норма & \\
V (фиброз) & Легочный фиброз, полости, буллы & $\uparrow /$ норма & \\
\hline
\end{tabular}


на то, что все другие исследования антифунгальной терапии АБЛА были неконтролируемыми, положительный эффект лечения был отмечен во всех сериях наблюдений. Результатом других множественных наблюдений также стало сушественное улучшение показателей функции внешнего дыхания и контроля над симптомами БА, снижение дозы или полная отмена сГКС после проведения курса лечения итраконазолом. Режимы дозирования этого препарата при АБЛА четко не регламентированы: обычно назначают от 200 до 400 мг в сутки (наши пациенты в большинстве случаев получали 200 мг в сутки), длительность лечения варьировалась от 2 до 8 мес. Фармакокинетика итраконазола хорошо изучена. Большинство авторов использовали дозу 200 мг в сутки. Указанная дозировка, согласно данным фармакокинетики, позволяет создавать необходимую антифунгальную концентрацию в легочной ткани при отсутствии выраженного токсического действия при довольно длительном применении. Большинство авторов отмечают, что польза от итраконазола перевешивает возможные токсические эффекты. Назначение итраконазола в более высоких дозах способствует проявлению его токсичности и существенно повышает стоимость лечения. Мы не отмечали большей эффективности лечения АБЛА при таких дозах. Сроки лечения в наших наблюдениях варьировались от 1 до 4 мес. В большинстве случаев мы использовали итраконазол в течение 6 нед. Обычно его принимают 1 раз в день утром во время еды. Необходимо учитывать возможные лекарственные взаимодействия препарата. Эффективность терапии оценивали по клиническим проявлениям и серологическим тестам, эозинофилии. Уровень общего IgE на фоне лечения ГКС понижается, но обычно остается высоким даже в период ремиссии.

Специфическое лечение способствует устранению воспаления, активизации системы мукоцилиарного клиренса, предотвращению повторной колонизации, а значит, и новых обострений АБЛА. Мы наблюдали ремиссию АБЛА в течение 6 лет после лечения преднизолоном и итраконазолом у молодой женщины.

Контроль над эффективностью терапии осуществляется преимущественно рентгенологическими и спирометрическими методами. Важна и оценка серологических параметров, поскольку позволяет определить необходимость проведения повторных курсов антифунгальной терапии еще до начала выраженных клинических проявлений. Следует помнить, что обострение симптомов БА после достижения ремиссии АБЛА может быть обусловлено не только обострением заболевания, но другими факторами, такими как вирусные инфекции. В подобных случаях проведение антифунгальной терапии не показано. Другие показатели крови, такие как эозинофилия, играют вспомогательную роль, однако рост числа эозинофилов наряду с клинической симптоматикой может указывать на наличие обострения АБЛА.

\section{Литература}

1. Hinson K.F., Moon A.J., Plummer N.S. Bronchopulmonary aspergillosis. Thorax 1952; 7: 317-333.

2. Henderson A.H., English M.P., Vecht R.J. Pulmonary aspergillosis: a survey of its occurrence in patients with chronic lung disease and a discussion of the significance of diagnostic tests. Thorax 1968; 25: 513-553.

3. Basich J.E., Graves T.S., Baz M.N. et al. Allergic bronchopulmonary aspergillosis in corticosteroid-dependent asthmatics. J. Allergy Clin. Immunol. 1981; 68: 98-102.

4. Chetty A., Bhargava S., Jain R.K. Allergic bronchopulmonary aspergillosis in Indian children with bronchial asthma. Ann. Allergy 1985; 54: 46-49.

5. Greenberger P.A., Patterson R. Allergic bronchopulmonary aspergillosis and the evaluation of the patient with asthma. J. Allergy Clin. Immunol. 1988; 81: 646-650.

6. Schwartz H.J., Greenberger P.A. The prevalence of allergic bronchopulmonary aspergillosis in patients with asthma, determined by serologic and radiologic criteria in patients at risk. J. Lab. Clin. Med. 1991; 117: 138-142.

7. Kumar R., Gaur S.N. Prevalence of allergic bronchopulmonary aspergillosis in patients with bronchial asthma. Asian Pac. J. Allergy Immunol. 2000; 18: 181-185.

8. Maurya V., Gugnani H.C., Sarma P.U. et al. Sensitization to Aspergillus antigens and occurrence of allergic bronchopulmonary aspergillosis in patients with asthma. Chest 2005; 127 (4): 1252-1259.

9. Кулешов А.В. Частота аспергиллезной инфекции у больных хронической обструктивной болезнью легких и бронхиальной астмой. Пробл. мед. микол. 2005; 7 (2): 66-67.

10. Eaton T., Garrett J., Milne D. et al. Allergic bronchopulmonary aspergillosis in the asthma clinic: a prospective evaluation of CT in the diagnostic algoritm. Chest 2000; 118: 66-72.

11. Митрофанов В.С., Свирщевская Е.В. Аспергиллез легких. СПб.: Фолиант; 2005.

12. Greenberger P.A. Clinical aspects of allergic bronchopulmonary aspergillosis. Front. Biosci. 2003; 8 (1): 119-127.

13. Patterson R., Greenberger P.A, Radin R.C., Roberts M. Allergic bronchopulmonary aspergillosis: staging as an aid to management. Ann. Intern. Med. 1982; 96: 286-291.

14. Walsh T.J., Anaissie E.J., Denning D.W. et al. Treatment of aspergillosis: Clinical practice guidelines of the Infectious Diseases Society of America. Clin. Infect. Dis. 2008; 46 (3): 327-360.

15. Erwin G.E., Fitzgerald J.E. Case report: allergic bronchopulmonary aspergillosis and allergic fungal sinusitis successfully treated with voriconazole. J. Asthma 2007; 44 (10): 891-895.

16. Wark P.A., Hensley M.J., Saltos N. et al. Anti-inflammatory effect of itraconazole in stable allergic bronchopulmonary aspergillosis: a randomized controlled trial. J. Allergy Clin. Immunol. 2003; 111 (5): 952-957.

\section{Информация об авторах}

Кулешов Андрей Владимирович - научный сотрудник ФГУ НИИ пульмонологии ФМБА России; тел.: (495) 465-52-64; e-mail: clinic@in-tegramed.ru Митрофанов Владимир Сергеевич - к. м. н., врач клиники НИИ медицинской микологии им. П.Н.Кашкина; тел.: (812) 510-36-12; e-mail: mycobiota@peterlink.ru

Свирщевская Елена Викторовна - к. б. н., старший научный сотрудник отдела иммунологии Института биоорганической химии им. М.М.Шемякина и Ю.А.Овчинникова; тел.: (495) 330-59-74

Поступила 03.08.09 (с) Коллектив авторов, 2009 удк 616.233/24-002.828-056.3 